\title{
DETERMINAÇÃO DO CALOR ESPECÍFICO DO RESÍDUO DE ACEROLA
}

\author{
B. H. O. PINHEIRO ${ }^{1}$, M. R. LEMES ${ }^{1}$, K. O. ARAUJO ${ }^{1}$, K. M. CHANG ${ }^{1}$, P. B. SILVA ${ }^{1}$, M. \\ A. S. BARROZO ${ }^{1}$, C. R. DUARTE ${ }^{1}$ \\ ${ }^{1}$ Universidade Federal de Uberlândia, Faculdade de Engenharia Química \\ E-mail para contato: bruno_okoti@hotmail.com
}

\begin{abstract}
RESUMO - A determinação do calor específico dos materiais é de grande importância em pesquisas com secagem, pois esta é uma propriedade necessária para o dimensionamento de equipamentos que envolvem transferência de calor e massa. Este trabalho teve como objetivo determinar experimentalmente o calor específico da semente de acerola, obtida a partir do processamento da fruta para produção de polpas e sucos. $\mathrm{O}$ calor específico foi determinado por calorimetria exploratória diferencial, no Instituto de Química da Universidade Federal de Uberlândia. Nas análises foram utilizadas de 5 a $8 \mathrm{mg}$ de amostra triturada, a taxa de aquecimento foi de $10{ }^{\circ} \mathrm{C} / \mathrm{min}$ para uma faixa de temperatura entre 20 e $90{ }^{\circ} \mathrm{C}$. Foram estudadas sementes com faixa de umidade variando de 6,7 a $81,2 \%$. Os cálculos para obtenção do calor específico foram realizados a partir do fluxo de calor. Os resultados mostraram a dependência do ${ }^{c} p$ em relação à temperatura e à umidade do material. Sendo mais acentuada para condições de umidade mais elevada.
\end{abstract}

\section{INTRODUÇÃO}

O fruto da acerola, conhecida também como cereja-das-antilhas ou cereja-de-Barbados, é originário da região compreendida ao sul do México, América Central e Norte da América do Sul (Mezadri et al., 2006). Segundo Oliveira et at. (1998), devido ao alto teor de vitamina $\mathrm{C}$ da acerola, o seu cultivo foi disseminado em várias regiões do mundo, tornando-se estável em ecossistemas tropicais e subtropicais do continente. Na década de 90, o plantio da acerola ganhou expressão econômica no Brasil e hoje está difundida praticamente em todo território nacional, com exceção das regiões que apresentam clima subtropical e/ou a de altitude, sujeitas a baixas temperaturas. Parte do volume de fruto in natura é destinada para operações de beneficiamento para produção de sucos, concentrados e néctares (Mezadri et al., 2008; Moreira et al., 2009). O Nordeste brasileiro concentra número expressivo dessas indústrias de beneficiamento, o que gera grande quantidade de resíduos de fruto, podendo atingir até 50\% da matérias-prima original (Lousada Junior et al., 2006; Rodrigues, 2006).

A secagem é uma das alternativas utilizada para o aproveitamento desses resíduos. Essa técnica possibilita a diversificação dos produtos, armazenamento por longos períodos em condições ambientais e a redução significativa de perdas nos períodos da safra (Gomes et al., 2004; Jesus et al., 2003; Brasileiro, 1999). 
A secagem de sementes de frutos carnosos, devido ao seu alto teor de umidade inicial, tende a envolver uma grande variação do teor de umidade, de modo que o efeito da umidade sobre as propriedades físicas destes materiais é de importante consideração na modelagem e simulação de processos. Uma característica física mais precisa das sementes em função do teor de umidade contribui para uma análise mais profunda do fenômeno de encolhimento, o qual tende a ocorrer durante a secagem de materiais com alto teor de umidade (PRADO, 2004).

Dentre as propriedades termo-físicas tem-se o calor específico que corresponde à energia necessária para alterar a temperatura da massa unitária do produto em um grau. Baseia-se estritamente na quantidade de energia requerida e não na taxa em que ocorre essa mudança de temperatura (FONTANA et al., 1999). Portanto, com vista a futuros trabalhos de modelagem e otimização dos secadores foi realizada a determinação do calor específico para os resíduos de acerola.

\section{MATERIAS E MÉTODOS}

\subsection{Material}

Para realização dos experimentos foram utilizados resíduos do processamento de acerola, especificamente as sementes de acerola, as quais foram fornecidas pela Fruteza LTDA, localizada no município de Dracena, SP.

\subsection{Métodos}

O calor específico foi determinado por calorimetria exploratória diferencial, no Instituto de Química da Universidade Federal de Uberlândia, os equipamentos utilizados para este procedimento deveriam ser manuseados somente por um funcionário do próprio Instituto devido à grande preocupação pela manutenção dos equipamentos. Nas análises foram utilizadas de 5 a $8 \mathrm{mg}$ de amostra triturada e uma taxa de aquecimento de $10^{\circ} \mathrm{C} / \mathrm{min}$ para uma faixa de temperatura entre 20 e $90^{\circ} \mathrm{C}$. Foram estudadas sementes com umidades iguais a 6,7; 10,$7 ; 16,9 ; 46,2 ; 63,1$ e $81,2 \%$. Os cálculos para obtenção do calor específico foram realizados de acordo com Kaletunç (2007) através da Equação 1.

$$
c_{p}=\frac{Q .60}{r . m}
$$

Em que ${ }^{c_{p}}$ corresponde ao calor específico, Q é a taxa de aquecimento, $r$ representa a taxa de aquecimento e $m$ a massa de amostra. 


\section{RESULTADOS E DISCUSSÕES}

Os resultados obtidos por DSC foram analisados por regressão não linear no software STATISTICA ${ }^{\circledR}$. A análise dos resultados mostrou que, para a ampla faixa de temperatura e umidade analisada, o calor específico para o resíduo de acerola apresenta comportamento não linear em relação a estas variáveis. É possível observar ainda que para temperaturas mais elevadas a variação do calor específico é mais acentuada (Figura 1). Marques (2008) em seu trabalho com acerola afirmou que o calor específico apresentava comportamento linear em relação à temperatura, isto para a faixa experimental de 20 a $55^{\circ} \mathrm{C}$. Contudo, para faixas mais ampla de temperatura o comportamento é cúbico em relação à temperatura. Este autor ressalta ainda grande variação do calor específico para a acerola madura, quando comparado com a acerola amarela. Provavelmente, esta variação está relacionada com o elevado teor de pectina total nesta fruta. Assim, a acerola madura fica muito sensível às mudanças na temperatura e no teor de umidade, que pode ocasionar a transição vítrea da fruta. Como resultado desta transição térmica, o calor específico sofre grandes aumentos em seu valor (ROOS,1995).

Os resultados da regressão para os efeitos significativos para o calor específico são apresentados na Tabela 1. Portanto, o calor específico pode ser representado pela Equação 2, que apresentou um valor de 0,813 para o quadrado do coeficiente de correlação da regressão. Em que $\mathrm{T}\left({ }^{\circ} \mathrm{C}\right)$ representa a temperatura e $\mathrm{M}(\mathrm{g} / \mathrm{g}$ amostra) a umidade do material.

Figura 1 -Calor específico dos resíduos de acerola.

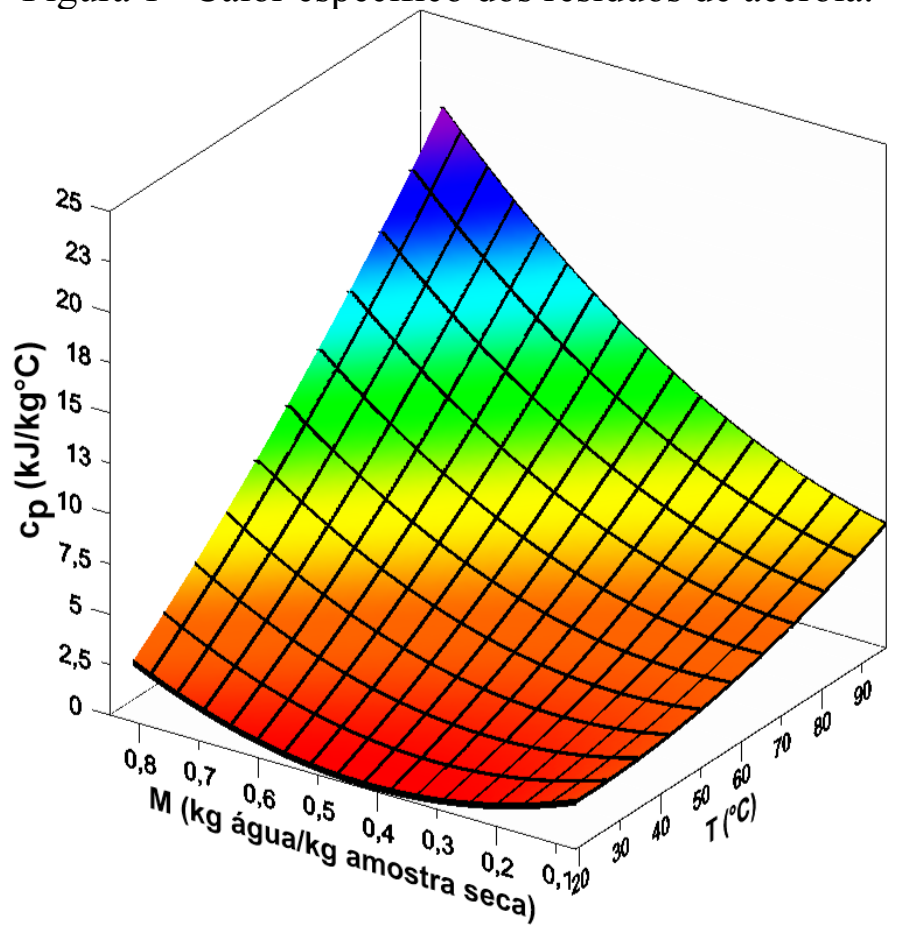

Tabela 1-Resultados da regressão múltipla para a resposta calor específico, considerando apenas os efeitos significativos.

Fator Parâmetro $\quad$ Desvio $\quad$ Nível de




\begin{tabular}{cccc}
\hline & & & significância \\
\hline Média $\left(\mathrm{kJ} / \mathrm{kg} .{ }^{\circ} \mathrm{C}\right)$ & 3,880 & 0,119 & $<0,001$ \\
\hline$T\left({ }^{\circ} \mathrm{C}\right)$ & $-0,047$ & 0,004 & $<0,001$ \\
\hline$M(\mathrm{~g} / \mathrm{g}$ amostra $)$ & $-19,184$ & 0,284 & $<0,001$ \\
\hline$T T$ & 0,0007 & $<0,001$ & $<0,001$ \\
\hline$M M$ & 17,578 & 0,299 & $<0,001$ \\
\hline$T M$ & 0,240 & 0,003 & $<0,001$ \\
\hline
\end{tabular}

$$
c_{p}=3,880-0,047 T-19,184 M+0,001 T^{2}+17,578 U M^{2}+0,240 T M
$$

\section{CONCLUSÃO}

Os resultados encontrados foram próximos aos relatados por Marques (2008). No entanto, este autor realizou as análises para o fruto (acerola) enquanto que no presente trabalho as análises foram para as sementes de acerola, o que justifica os valores abaixo dos encontrados por aquele autor, isto devido à menor umidade e diferença de composição. Estes resultados permitirão, em trabalhos futuros a modelagem e simulação de processos de transferência de energia no sistema. Vale ressaltar a escassez destas informações na literatura, fato que motivou a realização destas análises.

\section{REFERÊNCIAS}

BRASILEIRO, I. M. N. Cinética de secagem de acerola in natura em monocamada. 1999.80f. Dissertação (Mestrado em Engenharia Química) - Programa de PósGraduação em Química, Universidade Federal da Paraíba, Campina Grande.

FONTANA, A. J.; VARITH, J.; IKEDIALA, J.; REYES, J.; WACKER, B. Thermal properties of selected foods using a dual needle heat-pulse sensor. In ASAE/CSAE-SCGR 1999 MEETING, 1999, Toronto. Proceedings... St Joseph: ASAE, 1999, 10p.

GOMES, P. M. A.; FIGUEIRÊDO,R. M. F.; QUEIROZ, A. J. M. Armazenamento da polpa de acerola em pó a temperatura ambiente. Ciência e Tecnologia de Alimentos, Campinas, v.24, n.3, 2004.

JESUS, M. F.; SCARANTO, V. L.; JALALI, V. R. R.; SILVA, G. F. Produção de passas de acerola em secador de bandeja. Revista Brasileira de Produtos Agroindustriais, Campina Grande, v.5, n.1, p.81-87, 2003.

KALENTUNÇ, G. Prediction of specific heat of cereal flours: A quantitative empirical correlation. Journal of Food Engineering, v.82, p.589-594, oct., 2007. 
LOUSADA Júnior, J. E.; Costa, J. M. C.; Neiva, J. M. N.; Rodriguez, N. M. Caracterização físico-química de subprodutos obtidos do processamento de frutas tropicais visando seu aproveitamento na alimentação animal. Revista Animal Agronômica, v.37, p. 70-76, 2006.

MARQUES, L. G. Liofilização de frutas tropicais. Tese de doutorado, UFSCar. São Carlos, 2008.

MEZADRI, T.; FERNANDEZ-PACHON, M. S.; VILANO, D. El fruto de la acerola : composición y posibles usos alimenticios. Archivos Latinoamericanos de Nutrición, v.56, n.2, p.101-109, 2006.

MEZADRI, T; VILAÑO, D.; FERNÁNDEZ-PACHÓN, M.; GARCÍA-PARRILLA, M.; TRONCOSO, A. Antioxidant compounds and antioxidant activity in acerola (Malpighia emarginata DC.) fruits e derivatives. Journal of Food Composition and Analysis, v.21, n.4, p.282-290, 2008.

MOREIRA, G. E. G.; COSTA, G. M. G.; SOUZA A. C. R.; BRITO, E. S.; MEDEIROS, M. F. D.; AZEREDO, H. M. C. Physical properties of spray dried acerola pomace extract as affected by temperature and drying aids. Food Science and Technology v.42, p. 641$645,2009$.

OLIVEIRA, J. R. P.; FILHO, , W. S. S. Situação da cultura da acerola no Brasil e ações da Embrapa Mandioca Fruticultura em recursos energéticos e melhoramento. In: SIMPÓSIO DE RECURSOS GENÉTICOS E MELHORAMENTO DE PLANTAS PARA O NORDESTE DO BRASIL, 1998, Petrolina.

PRADO, M. M. Secagem em leito fixo de sementes com mucilagem.UFSCar. São Carlos, 2004.

RODRIGUEZ, J.; Mateos, J.; Nungaray, J.; Gonzáles, V.; Bhagnagar, T.; Roussos, S.; Cordova, J.; Baratti, J. Improving lipase production by nutrient source modification using Rhizopus homothallicus cultered in solid state fermentation. Process Biochemistry, v.41, n.11, p.2264-2269, 2006

ROOS, Y. Characterization of food polymers using state diagrams. Journal of Food Engineerig, v. 24, p. 339-360, 1995.

\section{AGRADECIMENTOS}

Agradecemos ao CNPQ e a Fundação de Amparo à Pesquisa do Estado de Minas Gerais (FAPEMIG) pelo apoio financeiro para a realização da pesquisa. 